\title{
Regional variability in drought as a function of the Atlantic Multidecadal Oscillation
}

\author{
Renée C. Elder ${ }^{*}$, Robert C. Balling, Jr., Randall S. Cerveny and Daniel Krahenbuhl \\ School of Geographical Sciences \& Urban Planning, Arizona State University, Tempe AZ 85287-5302 \\ Corresponding author: renee.elder@asu.edu
}

\begin{abstract}
The influence of the Atlantic Multidecadal Oscillation (AMO) produces pronounced regional variability in drought over the Caribbean, Central America and equatorial South America area. Through spatial statistical analyses, we identified a marked dichotomy between drought values of the Standardized Precipitation Evapotranspiration Index (SPEI) in northern Mexico and equatorial South America as a function of the AMO. The relationship is such that significant negative correlations between the drought index and phase of the AMO are identified for northern Mexico and on the Atlantic side of Central America. This indicates that drought (negative values of the SPEI) episodes are linked to the positive phase of the AMO. Alternately, there are high positive correlations between the AMO and on the Pacific side of Central America, the Caribbean and mainly in the northern South American area closest to the equator. Although many potential causes have been proposed in explanation of precipitation variability over the region, this geographic dichotomy suggests that movement of the Intertropical Convergence Zone (ITCZ) may play a significance role. The heightened vulnerability of the developing nations in this region to drought episodes makes forecasting droughts of great importance. These nations are greatly dependent on water intensive industries to maintain economic development. Thus, the findings of this research can assist in informing drought preparedness strategies to mitigate significant losses due to drought.
\end{abstract}

Keywords.-AMO, drought, Atlantic Ocean, ITCZ, Caribbean, Central America, equatorial South America

\section{INTRODUCTION}

Drought is one of the costliest disasters affecting the Small Island Developing States (SIDS) of the Caribbean that are dependent on agriculture and tourism. A changing climate will have great consequences for these places if precipitation decreases and evapotranspiration increases due to anticipated temperature increases (McCabe and Palecki 2006). Although changes will occur over both land and water, this paper focuses on the effects over land areas because our drought index is available only for land areas. Many Caribbean SIDS have limited to no natural resources, leaving them dependent on precipitation-intensive industries to maintain their economic development. Consequently, drought in the Caribbean is becoming an increasingly important climatic hazard. Waterintensive activities, such as agriculture, tourism, and farming rely heavily on a consistent and uniform rainfall over the area (Farrell et al. 2010). These activities in most countries represent the majority of their economic revenue and these activities make those countries very sensitive to short and long term drought.
Reduced water receipt can lead to significant water shortages in the Caribbean and Central America. Rainfall distribution in the Caribbean and Central America is particularly important during the dry season, during which the SIDS and Central American countries experience their greatest influx of tourists and, consequently, undergo greater domestic water demand (Farrell et al. 2010).

It is, therefore, of great importance to study drought in the Caribbean and Central America particularly because this region is among those who are most vulnerable to the presently changing climate. Accordingly, research that can aid in identifying the approach of extreme changes, such as drought, can mitigate further losses as these countries develop. In this paper drought is a period of time during which a location or region experiences a net water demand or P-PET is negative. Méndez and Magaña (2010) have identified that there is an evident signal in drought clusters between the Atlantic Multidecadal Oscillation (AMO) and the occurrence of drought in the Central American and Caribbean region. This study 
will numerically evaluate this relationship using the newly calculated Standardized Precipitation and Evapotranspiration Index (SPEI) together with a hot spot analysis to establish if there are significant drought regions in the study area responding to $\mathrm{AMO}$ variability.

\section{Regional Precipitation Tendencies and Drought}

Seasonality in the Caribbean and Central American is commonly measured not by thermal but rather by precipitation variations. A dry season generally occurs between November to April/May, while the region experiences a rainy season between May/June to November/ December with the latter accounting for 70$80 \%$ of the total annual rain (Farrell et al. 2010, Aguilar et al. 2005). Similarly, more than $60 \%$ of annual rainfall over Mexico is received during the boreal summer (Méndez and Magaña 2010).

However, there is greater variability in the timing, duration, and totals between the seasons. For example, some parts of the overall Caribbean/Central America region often experience short reductions in precipitation during the rainy season which is variable in timing over the region (Curtis and Gamble 2008, Farrell et al. 2010).

The distinct reduction between the two rainfall maxima, May to June and September to October, is most popularly known as the midsummer drought (MSD) (Giannini et al. 2000, Jury et al. 2007, Gamble et al. 2008, Curtis and Gamble 2008) and is attributed to intensification and expansion of the North Atlantic Subtropical High Pressure Cell (NAHP) into the region (Giannini et al. 2000, Gamble et al. 2008, Curtis and Gamble 2008). The effect of the NAHP on the MSD is not consistent throughout the entire Caribbean and Central American region displaying evident spatial variability in the timing of the rainfall reduction. The spatial inconsistency is likely due to the time that it takes for the NAHP to expand westward as the MSD tends to be first observed in the eastern Caribbean (June) and progresses westward (July) (Gamble et al. 2008, Giannini et al. 2000). Subsequently, the MSD becomes stronger and more significant from east to west, and reaches a maximum in the waters bounded by Jamaica, Cuba, and the Yucatan peninsula (Curtis and Gamble 2008).

Although it has been predicted with limited certainty that these regions can expect drier conditions in the future (IPCC 2007), studies have identified specific trends in past climate for the Caribbean and Central American region. Equatorial regions have received record low precipitation since 1995 while the Western Hemispheric subtropics have recovered from the reduced precipitation in the 1980s (Dore 2005). Moreover, in many cases while high rainfall intensity events are increasing, total precipitation has not shown such increases (Easterling et al. 2000, Farrell et al. 2010, Aguilar et al. 2005). This implies that there may be a greater number of dry days being experienced.

For the Caribbean, the annual total precipitation divided by the total number of days with precipitation $>1 \mathrm{~mm}$ shows a decrease though not significant due to dominant variability on the annual to decadal scales (Peterson et al. 2012). The annual maximum number of consecutive dry days (CDD), defined by $<1 \mathrm{~mm}$ of precipitation, is also decreasing while the number of heavy rainfall events is increasing (Peterson et al. 2012). In Central America, on the days it does rain the amount is increasing by $0.3 \mathrm{~mm} /$ decade while the summer maximum 1 day precipitation total is increasing by $1.7 \mathrm{~mm} /$ decade. Stations on the eastern side of the central isthmus and Columbia show decreases in maximum daily precipitation. Meanwhile, stations in northern Mexico and the eastern Caribbean portion of South America show increases in CDD (Peterson et al. 2012). Aguilar et al. (2005) found that there exists a positive correlation between the tropical Atlantic Ocean and precipitation indices in the region. Like the Caribbean, the intensity of precipitation, as it contributes to wet days, shows significant trends indicating that heavy precipitation events are increasing in the region. However, there has not been a decrease in the annual amount of precipitation during the last 40 
years in Central America (Aguilar et al. 2005). While some countries are experiencing positive changes in monthly or seasonal precipitation, it is most likely that there are increases in heavy and extreme precipitation events (Easterling et al. 2000, Dore 2005).

\section{Atlantic Multidecadal Oscillation} and the Central America/Caribbean/

\section{Northern South America Region}

To study the climatic impacts of drought in the Central American and Caribbean region, we have focused on one climatic teleconnection, the Atlantic Multidecadal Oscillation, as being particularly influential. The Atlantic Multidecadal Oscillation (AMO) is a nearglobal scale oscillatory mode defined by lowfrequency sea surface temperatures (SST) in the North Atlantic Ocean between $0^{\circ}$ and $70^{\circ} \mathrm{N}$ (McCabe and Palecki 2006, Wang et al. 2008, Knight et al. 2006). Its [AMO] effects on global climate are so significant that in recent years debate as to its linkage to anthropogenic global warming has started to be scientifically investigated (Zhou and Tong, 2012). A single mode represents the entire North Atlantic basin operating on multidecadal timescales of $30-80$ years, showing the greatest variations in the high latitudes of the North Atlantic (McCabe and Palecki 2006, Wang et al. 2008). The AMO features alternating warm and cool phases over large parts of the Northern Hemisphere which are believed to be driven by fluctuations in the strength of the Atlantic thermohaline circulation such that stronger (weaker) thermohaline circulation produces positive (negative) AMO (Knight et al. 2006, Klotzbach 2010). Cool AMO phases occurred in the 1900s-1920s and 1960s-1980s, while a warm phase occurred in the 1930s-1950s (Knight et al. 2006). The AMO is observed to have influences on the variability of precipitation distribution in many parts of the world thus it is important to identify those climatic processes it influences to determine how it can impact drought events in the most vulnerable places.

In particular, Caribbean hurricane activity has been linked to AMO variations and, additionally, significantly contributes to precipitation variability in the Caribbean and Central America. Multidecadal variations in major hurricane activity from 1944 to 2000 has been linked to AMO (Knight et al. 2006). The Atlantic Warm Pool (AWP), the Gulf of Mexico, Caribbean Sea, and western tropical North Atlantic, is an area of warm water which shows multidecadal variability of the AMO. Many Atlantic storms form or intensify over this warm pool thus, having a direct influence on the hurricane variability (Wang et al. 2008). Consequently, the multidecadal influence of AMO on the warm pool highlights the significance of the AMO to Atlantic hurricane activity. Additionally, hurricane variability is linked to a combination of ENSO phases with AMO; higher hurricane tracks are observed with positive AMO and strong La Niña and very few with negative AMO and strong El Niño (Klotzbach 2010).

Additionally, there have been studies identifying relationships between AMO and precipitation variations (including drought) in various areas including Africa, Europe, South America and the Caribbean. In southern Mexico, negative phases of AMO have been linked to drought while northwestern Mexico has experienced reduced maximum daily precipitation during the AMO's positive phase (Méndez and Magaña 2010). Méndez and Magaña (2010) also found that during wet periods in northern Mexico, there is reduced precipitation over and the Caribbean during the 1940s, 1970s, and 1980s, indicating an inverse relationship between the drought impacts experienced in the Caribbean and Central America compared to northern Mexico. Particularly for Mexico, it is observed that during positive (negative) AMO, northern Mexico (central and southern Mexico) will experience drought. 


\section{ATA}

Standardized Precipitation Evapotranspiration Index (SPEI)

Many different indicators have been used to study drought characteristics each with varying advantages and disadvantages. This study utilizes the Standardized Precipitation Evapotranspiration Index (SPEI), a recently calculated alternative measure of drought which can be used to identify, monitor and explore the consequences of climatic changes on drought (Vincente-Serrano et al. 2010a, 2010b). The SPEI has been used to identify main drought periods from the 1910 s to 2000 s with great accuracy (Vincente-Serrano et al. 2010a). The SPEI combines the advantages of the widely used Palmer Drought Severity Index (PDSI; Palmer 1965), which includes evapotranspiration and precipitation, and the Standardized Precipitation index (SPI; McKee et al. 1993), which allows mulitscalar investigations with a very high resolution. The index is calculated as the difference between monthly precipitation (P) and monthly potential evapotranspiration (PET) determined from Thornthwaite (1948) as:

$$
P E T=16 K\left(\frac{10 T}{I}\right)^{m}
$$

Eq. 1

where $T$ is the monthly mean temperature $\left({ }^{\circ} \mathrm{C}\right), I$ is an annual heat index calculated as the sum of 12 monthly values of $i$ :

$$
\begin{gathered}
i=\left(\frac{T}{5}\right)^{1.514} \\
m=6.75 \times 10^{-7} I^{3}-7.71 \times 10^{-5} I^{2} \\
-1.79 \times x^{2} I+0.492
\end{gathered}
$$

Eq. 3

The coefficient $\mathrm{K}$ is a function of latitude and month calculated:

$$
K=\left(\frac{N}{12}\right)\left(\frac{N D M}{30}\right)
$$

Eq. 4

where $\mathrm{N}$ is the maximum number of sun hours and NDM is the number of days of the month.

The difference between $\mathrm{P}$ and PET is aggregated at various time scales:

$$
D_{n}^{k}=\sum_{i=0}^{k-1}\left(P_{n-1}-P E T_{n-1}\right), \quad n \geq k
$$

Eq. 5

Where $\mathrm{k}$ (months) is the time scale of the aggregation and $\mathrm{n}$ is the calculation number. $\mathrm{A}$ log-logistic probability function is then fitted to the data series of D (Vicente-Serrano et al. 2010a, 2010b).

SPEI data are available for 1901 to 2006 at $0.5^{\circ}$ latitude by $0.5^{\circ}$ longitude resolution for land areas globally with values typically ranging from -2.5 (drought) to 2.5 (wet). Only grid point locations for which SPEI data exist are shown in the SPEI analysis figures (e.g., Figure 2-4). This study utilizes the one-month time scale SPEI for the years 1948 to 2006 .

\section{Atlantic Multidecadal Oscillation}

Additionally, we use the unsmoothed AMO time series from the National Oceanic and Atmospheric Administration's (NOAA) Earth Systems Research Laboratory (http://www.esrl. noaa.gov/psd/data/correlation/amon.us.data) which is calculated by NOAA Physical Science Division from the KAPLAN SST dataset

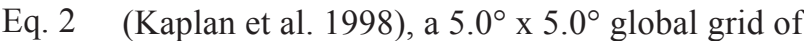
SST anomalies. These data are available for the period 1948 to present. For this study, we are using data from 1948 to 2006 (Figure 1).

\section{AnAlysis}

The domain of the study area is $0^{\circ}$ to $30^{\circ} \mathrm{N}$ and $53^{\circ} \mathrm{W}$ to $120^{\circ} \mathrm{W}$, including the Caribbean, Central America and a small area of northern 


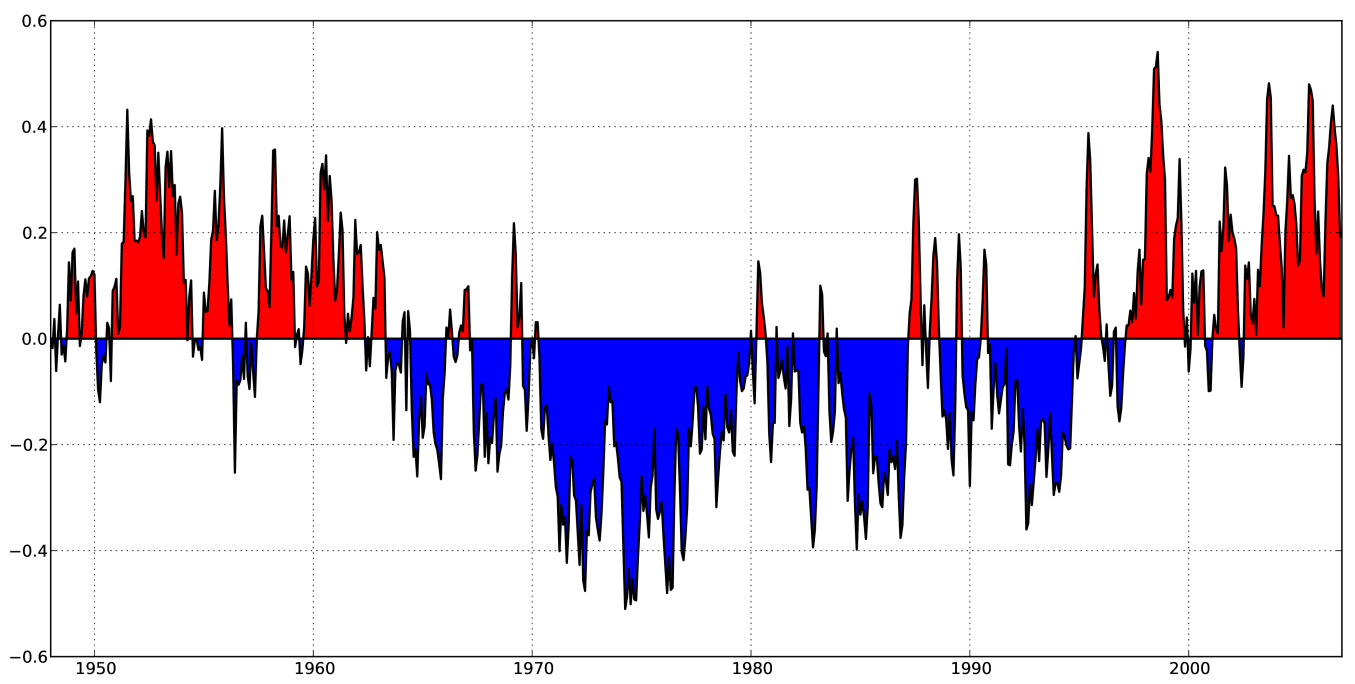

FIG. 1. Atlantic Multidecadal Oscillation for years 1948 through 2006.

South America. For the entire area, the SPEI data yields 1973 grid points, each $0.5^{\circ}$ by $0.5^{\circ}$, which are used to perform the analysis.

First, we employed a Student's t-test to compare the mean of the drought values for each grid point during positive phases of the AMO to the mean of the drought values for each grid point during the negative phases for the years 1948 to 2006. The Student's t-values are determined as (Ott and Longnecker 2004):

$$
t=\frac{\bar{x}_{1}-\bar{x}_{2}}{\sqrt{\frac{s_{1}^{2}}{n_{1}}+\frac{s_{2}^{2}}{n_{2}}}}
$$

Eq. 6

where $\bar{x}_{1}, s_{1}^{2}$, and $n_{1}$ are the mean, the variance and the total number of drought values for negative AMO and $\bar{x}_{2}, s_{2}^{2}, n_{2}$ are the mean, the variance and the total number of drought values for positive AMO.

This is completed both for the monthly values through the year and also by climatologic seasons.
To refine that analysis, we performed a hot spot analysis using the Getis-Ord $G_{i}^{*}$ statistic employing the resultant t-values. This statistic tests where clusters of high and low values are located by measuring the degree of association from concentrations of weighted points and all weighted points within radius, $d$, of a point of interest, $i=1,2,3, \ldots, n$ whose coordinates are known and whose value, $x$, is obtained from variable $X$, the sum of all $x$ values (i.e. the sum of all t-values) (Getis and Ord 1992). The statistic tests hypotheses about the concentration of the sum of $x$ values associated with $j$ points within distance $d$ of point $i$ (Getis and Ord 1992). The resultant values for each grid point is a z-score where larger (smaller) statistically significant positive (negative) values means there is an more significant concentration of high (low) values, termed a "hot spot" (“cold spot") (ESRI 2009).

The Getis-Ord $G_{i}^{*}$ statistic is determined as:

$$
G_{i}^{*}=\frac{\sum_{j=1}^{n} w_{i, j} x_{j}-\bar{X} \sum_{j=1}^{n} w_{i, j}}{S \sqrt{\frac{\left[n \sum_{j=1}^{n} w_{i, j}^{2}-\left(\sum_{j=1}^{n} w_{i, j}\right)^{2}\right]}{n-1}}}
$$


Where $w_{i, j}$ is the spatial weight between point $i$ and point $j, n$ is the number of points and $\bar{X}$ and $S$ are determined as follows:

$$
\begin{gathered}
\bar{X}=\frac{\sum_{j=1}^{n} x_{j}}{n} \\
S=\sqrt{\frac{\sum_{j=1}^{n} x_{j}^{2}}{n}-\overline{(X)}^{2}}
\end{gathered}
$$

Eq. 8

Eq. 9

The Getis-Ord statistic can be plotted and distinct "hot spots," spatially contiguous regions of highest and lowest correlations, can be identified.

\section{Discussion}

Mapping of the statistically significant $(\alpha=0.05) \quad t$-values generated from the Student's t-test (Figure 2) illustrates an inverse relationship between northern Mexico and the Central America/Caribbean/northern Southern America region with respect to the AMO phase. There is a higher population of large positive $\mathrm{t}$-values in northern Mexico with minor ones in Central America and northern South America and a higher population of large negative t-values mainly in the northern South American area closest to the equator.

The plotted z-scores generated from the Getis-Ord statistic illustrate a marked dichotomy (Figure 3). A geographically inverse relationship is evident such that high negative relationship between the drought index and phase of the Atlantic Multidecadal Oscillation (AMO) are identified for northern Mexico and on the Atlantic side of Central America. This indicates that more severe drought (negative values of the SPEI) episodes are linked to the positive phase of the AMO in northern Mexico. Alternately, there are high positive relationships between the AMO phase and on the Pacific side of Central America, the Caribbean and primarily in northern South American area closest to the equator indicating drier conditions there during the negative phase of the AMO.

Smaller scale relationships in moisture patterns between the AMO phases are identified when these data are analyzed seasonally (Figure 4). During the winter season, the beginning of the dry season for most of the region, there is a tendency toward an inverse relationship with the AMO between southern Mexico SPEI values and SPEI values near coastal northern

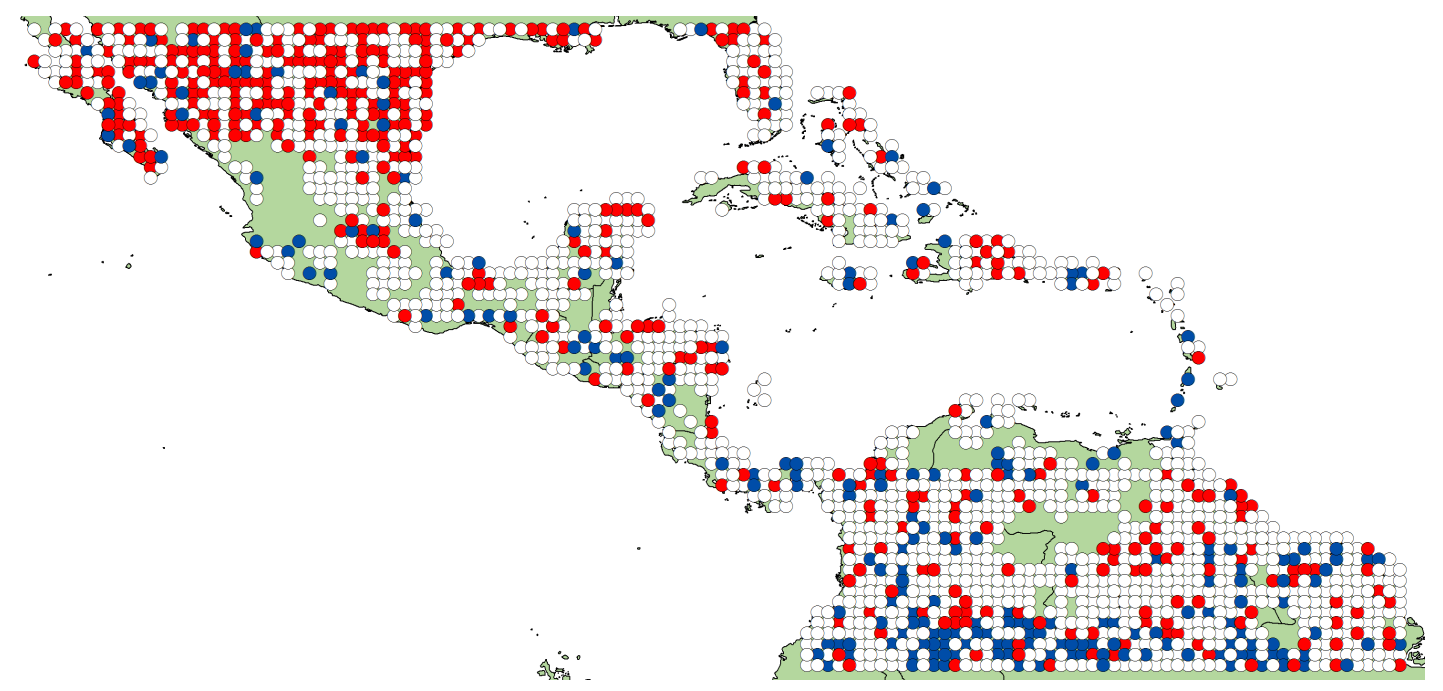

FIG. 2. Plotted raw t-values for all years 1948 to 2006. Red indicates a significant positive t-value (SPEI difference between AMO positive and negative phases at 95\%), white indicates no significant t-values, and blue indicates a significant negative t-value). 


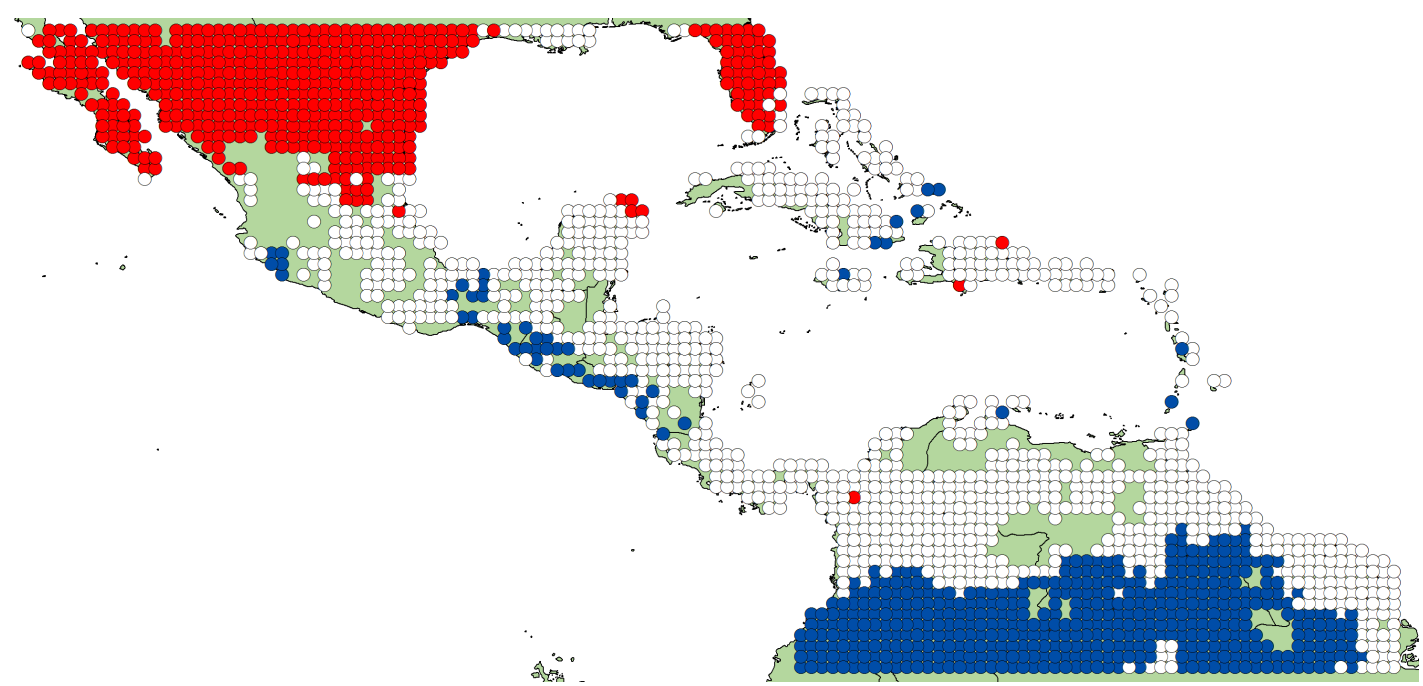

FIG. 3. Plotted z-scores generated by $G_{i}^{*}$ statistic for all years 1948 to 2006 . Red indicates significant positive z-scores, white indicates no significant $\mathrm{z}$-scores, and blue indicates significant negative $\mathrm{z}$-scores.
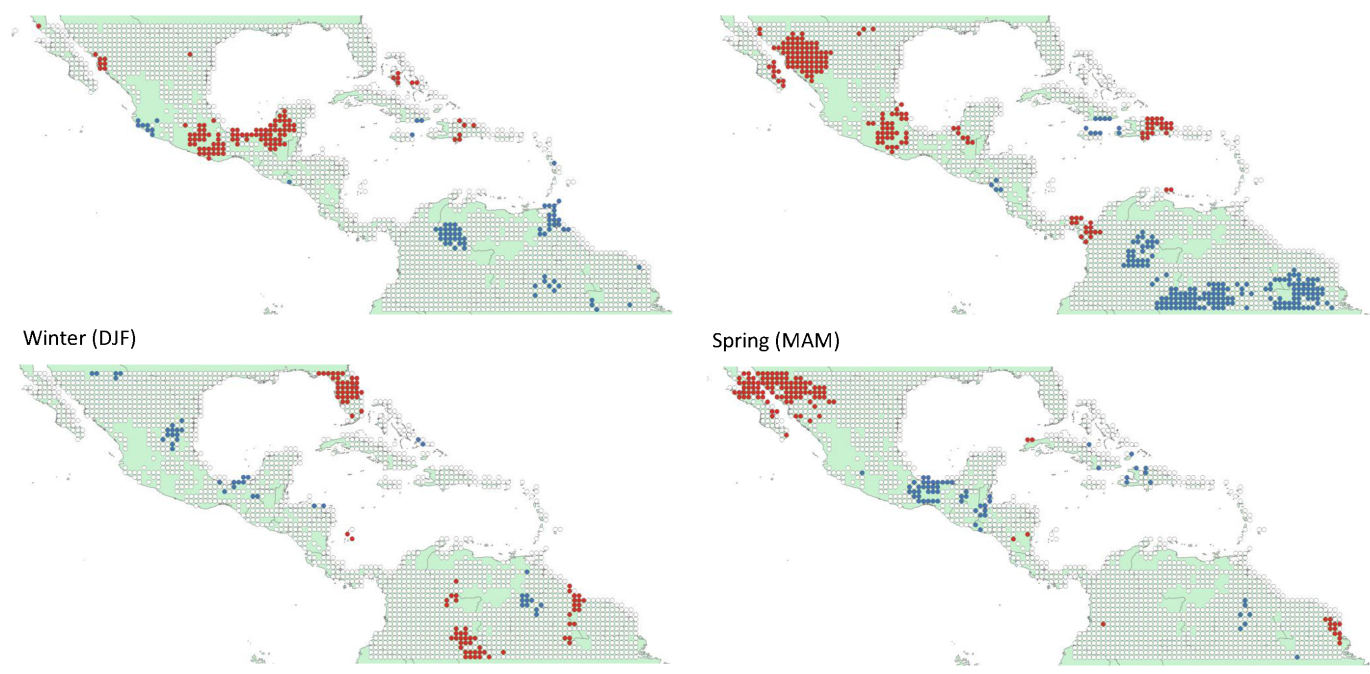

Summer (JJA)

Fall (SON)

FIG. 4. Plotted z-scores generated by $G_{i}^{*}$ statistic for each climatological season for all years 1948 to 2006 . Red indicates significant positive z-scores, white indicates no significant $\mathrm{z}$-scores, and blue indicates significant negative z-scores.

South America and the southern Caribbean. Spring, the second half of the dry season, shows a similar relationship as seen with the annual mapping; a marked dichotomy in the response to AMO between SPEI values in northern Mexico and northern South America nearest the equator during each phase. There is also a subtle inverse relationship observed through the dry season (DJFMAM) between the southeastern Cuba /northern Jamaica/ western, coastal Haiti region and Dominican Republic. Summer, the beginning of the rainy season, does not 
show much clustering of the drought index in response to the AMO; there is sparse negative clustering in southern Mexico and sparse positive clustering near the equator. Fall, the latter half of the rainy season, shows the inverse relationship with AMO between northern and southern Mexico drought values. This implies that the AMO influences the region differently between seasons.

Several mechanisms to explain the northern aspect of this relationship of more extreme drought with positive phase of the AMO have been proposed in the literature. With warmer waters in the Atlantic Ocean, associated with the positive phase of the AMO, increased convection occurs in the region and thus increased precipitation (Zeng et al. 2008). Another cause of the alternation in dryness with AMO phase may be the displacement of the Inter-tropical Convergence Zone (ITCZ). Rao and colleagues (1995) have noted that "... enhanced northward temperature increase in the tropical Atlantic is accompanied by a stronger meridional pressure gradient and an accelerated southerly wind component, which are representative of a northward displacement of the ITCZ" (697).

Northward displacement of the ITCZ, under the positive phase of the AMO, would likely influence increased moisture advection and lift over southern Mexico, Central America and the Caribbean with subsidence occurring over northern Mexico. Consequently, when North Atlantic waters are not anomalously warmer than the tropical South Atlantic, the ITCZ will be situated at a lower latitude resulting in increased moisture advection and convergence nearer the equator or in the southern hemisphere. Additionally, displacement of the ITCZ affects the Hadley cell which can alter atmospheric moisture flux divergence and convergence and subsidence (e.g., Méndez and Magaña 2010).

In northern South America, the positive clustering between the SPEI and AMO is concentrated nearest the equator; this area contains the northernmost part of the Amazon Basin. Drought in the Amazon is frequently attributed to ENSO; however, it has also been strongly connected to SST anomalies in the North Atlantic Ocean, e.g., 2005 and 2010 Amazon droughts (Lewis et al. 2011). Ascending motion in the atmosphere over the north Atlantic, due to warmer SST, results in subsidence over the South Atlantic and the Amazon Basin (Zeng et al. 2008). Downward motion in the south induces increased moisture divergence over the Amazon basin resulting in low rainfall and moisture conditions in parts of the Amazon Basin and north eastern Brazil (e.g., Zeng et al. 2008, Enfield and Alfaro 1999, Nobre and Shukla 1996).

As previously mentioned, the Atlantic Warm Pool (AWP) is linked to the AMO (Wang et al. 2008). During the positive (negative) phase of AMO, there is likely to be significantly warmer (cooler) waters confined in this area inducing increased (lessened) convective activity. Increased convection will generate more easterly waves which propagate westward bringing moisture and precipitation in to Central America. Furthermore, easterly waves may become tropical storms many of which become hurricanes over the AWP which would bring additional precipitation to the Caribbean and Central America. Decreased precipitation in Southern Mexico is linked to reduced easterly wave action (e.g., Méndez and Magaña 2010).

Another proposed mechanism influencing drought in this region is the Caribbean Low Level Jet (CLLJ), the result of intensification of the trade winds in the western Caribbean basin near $925 \mathrm{mb}$ with a horizontal maximum of up to $16 \mathrm{~m} / \mathrm{s}$ (Whyte et al. 2008, Wang and Lee 2007). Variability in the strength of the CLLJ is linked to the variability in zonal SST gradients in the equatorial Pacific and Atlantic Oceans (Whyte 2008). The strengthening of the trades intensifies lift and supplies moisture and heavy precipitation to the Caribbean coast of Central America (Whyte et al. 2008, Wang and Lee 2007). Dryness prevails in the Caribbean basin when the CLLJ is strong which is associated with cooler SST in the tropical North Atlantic Ocean and warmer SST in the equatorial Pacific Ocean attributed to El Niño (Whyte et al. 2008).

Weaker trade winds favor easterly waves and thus more tropical cyclones so the intensity 
of the CLLJ influences easterly wave activity in the Gulf of Mexico and the Caribbean Sea. Weak CLLJ produces increased precipitation over the Caribbean, Central America and southern Mexico and reduced precipitation over northern Mexico. Moreover, a strong CLLJ inhibits easterly wave action influencing reduced precipitation in Central America and southern Mexico (Méndez and Magaña 2010). Meanwhile in northern Mexico, easterly waves above $20^{\circ} \mathrm{N}$ bring rainfall. Increased dryness in northern Mexico may result from easterly waves over the Gulf of Mexico that do not travel far enough north, attributed to differences in barotropic instability, compared to the easterly waves over the Caribbean Sea (Méndez and Magaña 2010). This indicates that during a positive AMO phase, the warmer SSTs break down the speed of the CLLJ resulting in increased easterly wave action and thus more rainfall in the Caribbean, Central America, and southern Mexico.

During the positive phase of the AMO, northern Mexico is drier than during the negative phase. Conversely, during the positive phase of the AMO, equatorial South America is wetter than during the negative phase. Considering that the ITCZ migrates to the north when SSTs are high in the North Atlantic Ocean there is expected to also be a shift in the positioning of the subtropical high pressure cells. To determine the influence of this shift, we employ the National Center for Environmental Protection (NCEP) Reanalysis Project (Kalnay et al. 1996) to create the mean $500 \mathrm{hPa}$ height field for 1974 (negative AMO) and 2005 (positive AMO) (Figure 5) to determine major synoptic features for the study area under different phases of the AMO.

For the positive AMO, the subtropical high extends south toward the equator. Because the cell extends so far south, it influences the moisture in that region; rotating winds draw moisture from the ITCZ. This may account for why the southern Amazon Basin is dry when Atlantic SSTs are warm (positive AMO). Specifically, the ITCZ moisture is advected out of the region along the anticyclonic flow and to the north such that there is little moisture left south of the equator for rainfall. The placement of the subtropical high also influences Pacific storm tracks. With the high pressure extending far out into the Pacific, storms are diverted northward into the United States leaving northern Mexico drier.

During the negative phase of the AMO, we see that the high pressure retracts and is no longer as large as with the intense positive phase. As it does not extend as far out into the Pacific Ocean,
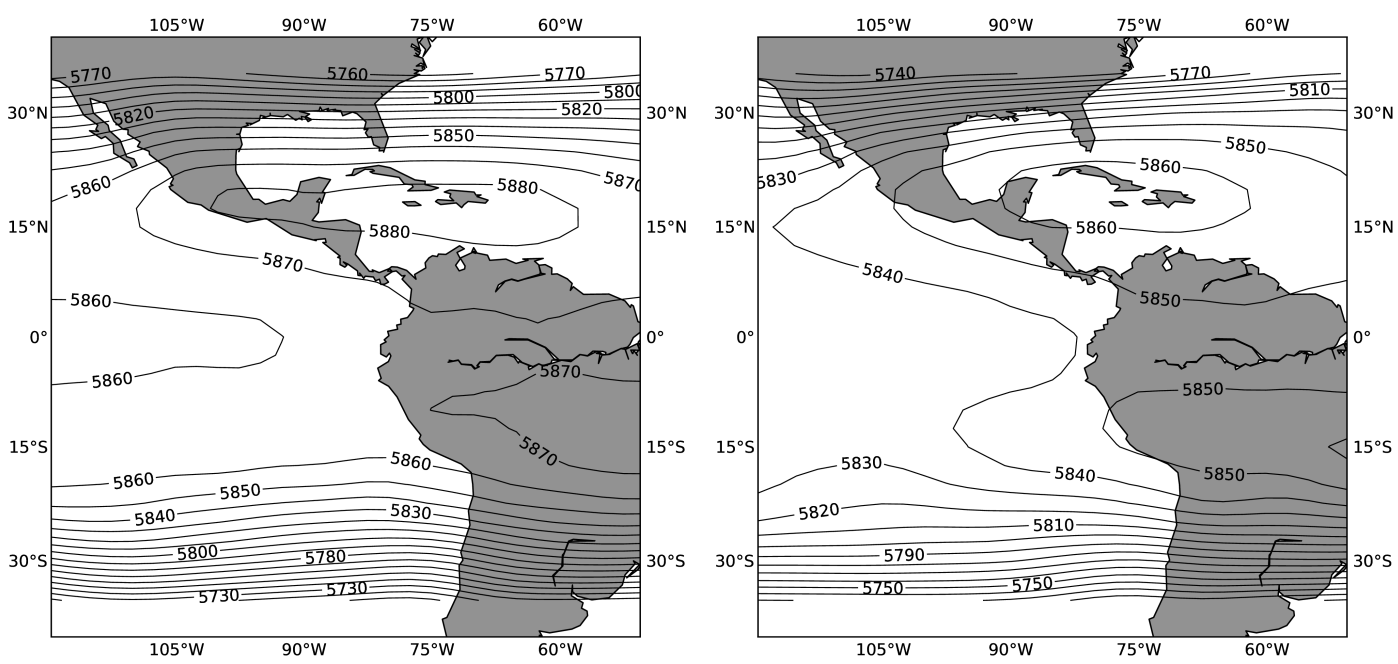

FIg. 5. Average $500 \mathrm{hPa}$ height field (meters) for 1974 (negative AMO) (Right) and average $500 \mathrm{hPa}$ height field (meters) for 2005 (positive AMO) (Left) using data from the NCEP Reanalysis Project (Kalnay et al., 1996). 
moisture is transported into northern Mexico and storm tracks are also allowed to move further south bringing wetter conditions. The ITCZ is also situated in the southern hemisphere implying there is moisture convergence over the Amazon Basin.

To support this we have utilized $1.0^{\circ} \times 1.0^{\circ}$ grid of monthly surface precipitation totals from the Global Precipitation Climatology Center's reanalysis version 6 (Schneider et al. 2011), to visualize the inverse relationship in precipitation within the study region during 1974 (negative AMO) and 2005 (positive AMO) (Figure 6).
The average precipitation for these years clearly demonstrates the relationship indicated by the hot spot analysis (Figure 3).

Furthermore, we analyzed the $2.5^{\circ} \times 2.5^{\circ}$ grid of zonal wind monthly means from the NCEP Reanalysis Project (Kalnay et al. 1996) to determine any changes in the Hadley Cell. We calculated the mean zonal wind for seventeen pressure levels from 1000 to $10 \mathrm{hPa}$ for the years 1974 (negative AMO) and 2005 (positive AMO) (Figure 7). This figure however does not show much difference between the negative and positive AMO years.
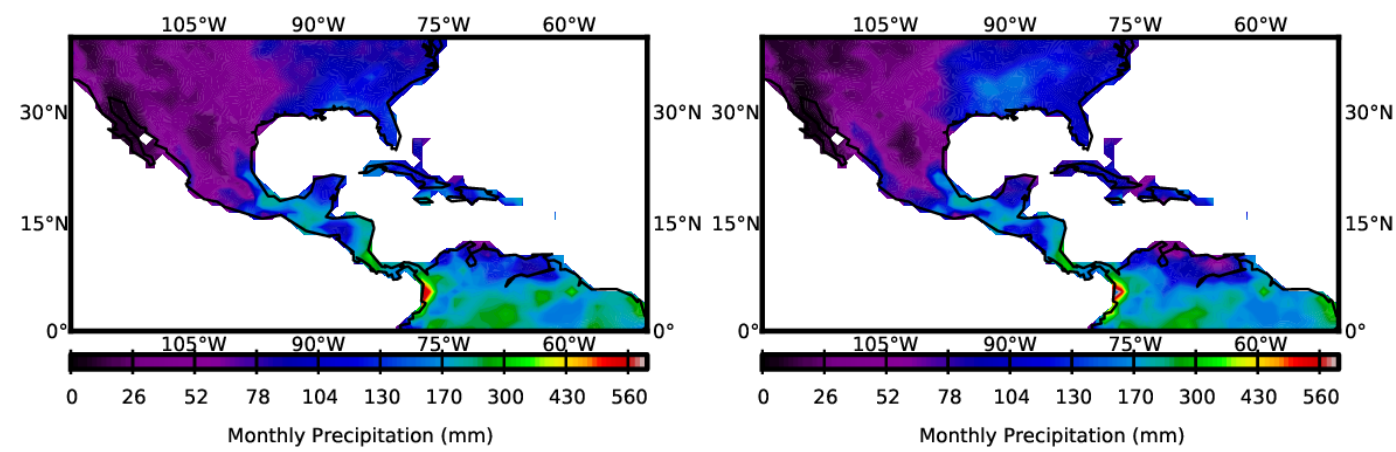

FIG. 6. Average precipitation (mm) for 1974 (negative AMO) (Right) and average precipitation (mm) for 2005 (positive AMO) (Left) using data from the Global Precipitation Climatology Center's Reanalysis Version 6 (Schneider et al., 2011).
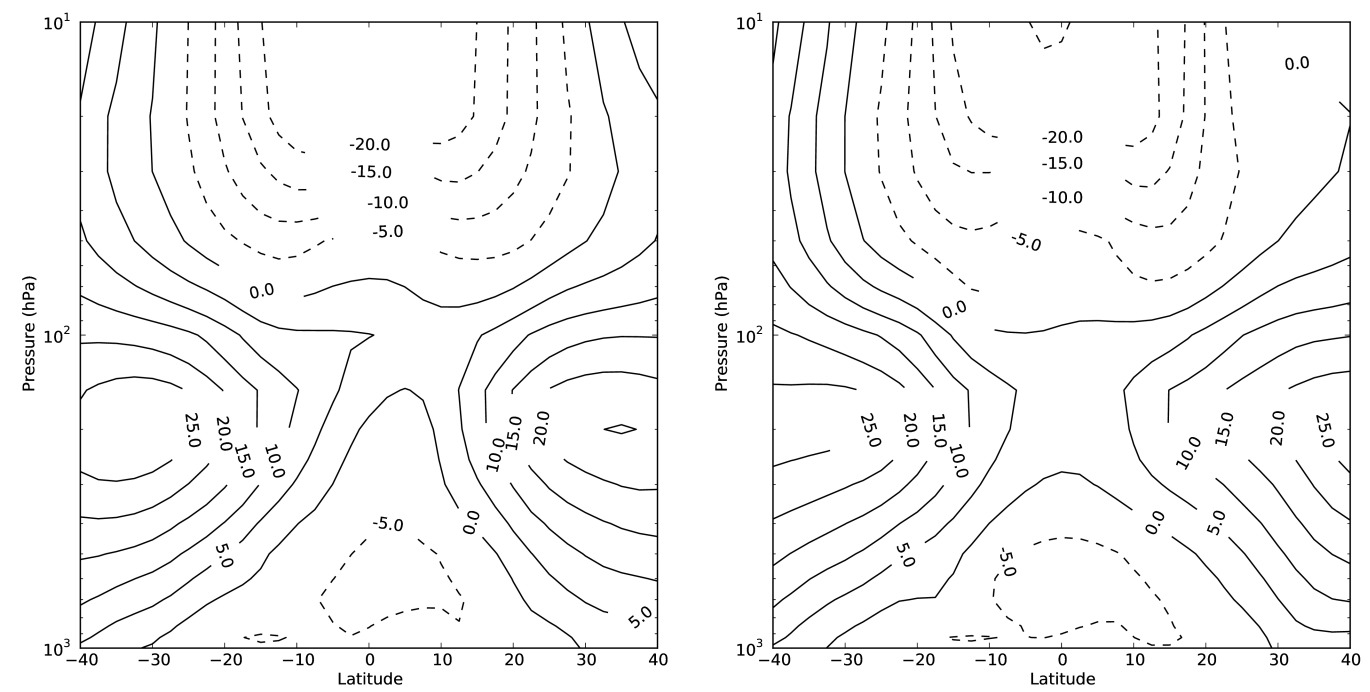

Fig. 7. Average zonal wind from $1000 \mathrm{hPa}$ to $10 \mathrm{hPa}$ for 1974 (negative AMO) (Right) and average zonal wind from $1000 \mathrm{hPa}$ to $10 \mathrm{hPa}$ for 2005 (positive AMO) (Left) using data from the NCEP Reanalysis Project (Kalnay et al., 1996). 


\section{Conclusion}

In this study, we have examined the influence of the Atlantic Multidecadal Oscillation (AMO) on drought over the Caribbean, Central America and equatorial South America area. Through spatial statistical analyses, we identified a marked dichotomy response between drought values of the Standardized Precipitation Evapotranspiration Index (SPEI) in northern Mexico and equatorial South America as a function of the AMO. Past studies have identified alternative forcing mechanisms that modify precipitation patterns in the western tropics such as ENSO, NAO (see Giannini et al. 2000, Taylor et al. 2002, Chen and Taylor 2002, Jury et al 2007), and Saharan dust transport (Prospero1996, Prospero and MayolBracero 2013), however, we chose to focus on the relationship between drought and the AMO. The relationship is such that significant negative correlations between the drought index and phase of the AMO are identified for northern Mexico and the Atlantic side of Central America. This indicates that drought (negative values of the SPEI) episodes are linked to the positive phase of the AMO. Alternately, there are high positive correlations between the AMO and the Pacific side of Central America, the Caribbean and mainly in northern South American area closest to the equator. Although many potential causes have been proposed in explanation of precipitation variability over the region, this geographic dichotomy suggests that movement of the Intertropical Convergence Zone (ITCZ) may play a significant role.

When the ITCZ is shifted northward there is subsidence over the Amazon Basin and northern Mexico however it seems the size of the subtropical high influences the transport of moisture away from the Amazon Basin. Generally, during positive AMO the subtropical high may expand east-west and north -south influencing moisture advection along equatorial South America, moisture divergence from the Amazon Basin and diverging storm tracks away from northern Mexico. During the negative $\mathrm{AMO}$, the subtropical high retracts and moisture diverges away from the equatorial South
American region and pumped into northern Mexico. Zeng et al. (2008) found that high SSTs in the northern Atlantic Ocean resulted in drought over the Amazon Basin. While this may be true for the south and western Amazon, the northernmost part of the Amazon Basin is impacted differently noting the spatial inconsistency of the influence of warm SSTs in the northern Atlantic Ocean. Additionally, southern Mexico, Central America and the Caribbean experience wetter (drier) conditions during positive AMO (negative AMO) most likely due to the influence of the CLLJ.

The heightened vulnerability of the developing nations in this region to drought episodes makes forecasting droughts of great importance to them. These nations are greatly dependent on water intensive industries to maintain economic development. Thus, the findings of this research can assist in informing drought preparedness strategies to mitigate significant losses due to drought.

Acknowledgements.-Kaplan SST VS data and NCEP Reanalysis data provided by the NOAA/OAR/ESRL PSD, Boulder, Colorado, USA, from their website at http://esrl.noaa.gov/ $\mathrm{psd} /$.

\section{Literature Cited}

Aguilar, E., et al. 2005. Changes in precipitation and temperature extremes in Central America and northern South America, 1961-2003, J. Geophys. Res. 110: D23107, doi:10.1029/2005JD006119.

Chen, A. and M. Taylor. 2002. Investigating the link between early season Baribbean rainfall and the El Niño +1 year. Int. J. Climatol. 22:87-106.

Curtis, S and D. W. Gamble. 2008. Regional variables in the Caribbean mid-summer drought. Theoret. App. Climatol. 94:25-34, doi:10.1007/s00704-007-03420 .

Dore, M. H.I. 2005. Climate change and changes in global precipitation patterns: what do we know? Envi. Int. 31:1167-1181, doi: 10.1016/j.envint.2005.03.004.

Easterling, D.R. et al. 2000. Climate Extremes: Observations, Modeling and Impacts. Science 289:2068 - 2074, doi:10.1126/ science.289.5487.2068 (2068-2074). 
Enfield, D. B. and E. J. Alfaro. 1999. The Dependence of Caribbean Rainfall on the Interaction of the Tropical Atlantic and Pacific Oceans. J. Climate 12:2093-2103, doi:http://dx.doi.org/10.1175/15200442(1999)012<2093:TDOCRO >2.0.CO;2.

ESRI. 2009. ArcGIS Desktop 9.3 Help - How Hot Spot Ananlysis: Getis-Ord Gi* (Spatial Statistics) Works. http://webhelp.esri.com/ARCGISDESKTOP/9.3/ index.cfm? TopicName $=$ Hot_Spot_Analysis_ (Getis-Ord_Gi*)_(Spatial_Statistics).

Farrell, D., A. Trotman and C. Cox. 2010. Drought early warning and risk reduction: A case study of the Caribbean drought of 2009-2010. UNISDR: Global Assessment Report on Disaster Risk Reduction. $1-22$.

Gamble, Douglas A., Darren B. Parnell and Scott Curtis. 2008. Spatial variability of the Caribbean midsummer drought and relation to north Atlantic high circulation. Int. J. Climatol. 28:343-350, doi:10.1002/joc. 1600 .

Getis, A. and J. K. Ord. 1992. The Analysis of Spatial Association by Use of Distance Statistics. Geographical Analysis. 24:189-206, doi:10.1111/j.1538-4632.1992.tb00261.x.

Giannini A, Y Kushnir, and MA Cane. 2000. Interannual variability of Caribbean rainfall, ENSO, and the Atlantic Ocean. J. Climate 13:297 - 311.

Jury, M., B. Malmgren and A. Winter. 2007. Subregional precipitation climate of the Caribbean and relationships with ENSO and NAO. J. Geophys. Res. 112:D16107, doi:10.1029/2006JD007541.

Kalnay et al. 1996. The NCEP/NCAR 40-year reanalysis project. Bull. Amer. Meteor. Soc. 77:437-470, doi:http://dx.doi.org/10.1175/15200477(1996)077<0437:TNYRP>2.0.CO;2.

Kaplan, A., M.A. Cane, Y. Kushnir, A. C. Clement, M. Benno Blumenthal, and B. Rajagopalan. 1998. Analyses of global sea surface temperature 18561991. J. Geophys. Res. 103(C9):18567-18589, doi:10.1029/97JC01736.

Klotzbach, P. J. 2011: El Niño-Southern Oscillation's Impact on Atlantic Basin Hurricanes and U.S. Landfalls. J. Climate 24:1252-1263, doi:http:// dx.doi.org/10.1175/2010JCLI3799.1.

Knight, J. R., C. K. Folland, and A. A. Scaife. 2006. Climate impacts of the Atlantic Multidecadal Oscillation. Geophys. Res. Lett. 33:L17706, doi:10.1029/2006GL026242.

Lewis, S. L. et al. 2011. The 2010 Amazon Drought. Science 331(6017):554, doi:10.1126/ science. 1200807.

McCabe, G. J. and M. A. Palecki. 2006. Multidecadal climate variability of global lands and oceans. Int. J. Climatol. 26:849-865, doi:10.1002/joc.1289.
McKee, T. B. N. J. Doeskin, and J. Kleist. 1993. The Relationship of Drought Frequency and Duration to Time Scales. Proc. 8th Conf. on Applied Climatology, January 17-22, 1993. American Meteorological Society, Boston, Massachusetts, pp. 179-184.

Méndez M. and V. Magaña. 2010. Regional Aspects of Prolonged Meteorological Droughts over Mexico and Central America. J. Climate 23:1175-1188, doi:10.1175/2009JCLI3080.1.

Nobre P. and J. Shukla. 1996. Variations in Sea Surface Temperature, Wind Stress, and Rainfall over the Tropical Atlantic and South America. J. Climate 9:2464-2479, doi:http://dx.doi.org/10.1175/15200442(1996)009<2464:VOSSTW>2.0.CO;2.

Ott, R. L. and M.T. Longnecker. 2004. A First Course in Statistical Methods. USA: Brooks/Cole.

Palmer, W. C., 1965. Meteorological Drought. U.S. Weather Bureau. Research Paper 45, US. Dept. of Commerce, Washington, D.C., 58 p.

Peterson, T. C., et al. 2002. Recent changes in climate extremes in the Caribbean region, J. Geophys. Res. 107(D21):4601, doi:10.1029/2002JD002251.

Prospero, J. M. 1996. Saharan dust transport over the North Atlantic Ocean and Mediterranean: An overview. In The impact of desert dust across the Mediterranean, ed. S. Guerzoni and R. Chester, 133-151. Springer Netherlands.

Prospero, Joseph M. and Olga L. Mayol-Bracero. 2013. Understanding the Transport and Impact of African Dust on the Caribbean Basin. Bull. Amer. Meteor. Soc. 94:1329-1337, doi:http://dx.doi.org/10.1175/ BAMS-D-12-00142.1.

Rao, V. B., K. Hada and D.L. Herdies. 1995. On the severe drought of 1993 in north-east Brazil. Int. J. Climatol. 15:697-704, doi:10.1002/joc.3370150608.

Schneider, Udo; Becker, Andreas; Finger, Peter; MeyerChristoffer, Anja; Rudolf, Bruno; Ziese, Markus. 2011. GPCC Full Data Reanalysis Version 6.0 at 2.5 : Monthly Land-Surface Precipitation from Rain-Gauges built on GTS-based and Historic Data, doi:10.5676/DWD_GPCC/FD_M_V6_250.

Thornthwaite, C. W. 1948. An approach toward a rational classification of climate. Geographic Review 38:5594.

Vicente-Serrano, S. M., S. Beguería, J. I. López-Moreno. 2010a. A Multiscalar Drought Index Sensitive to Global Warming: The Standardized Precipitation Evapotranspiration Index. J. Climate 23:1696-1718, doi:http://dx.doi.org/10.1175/2009JCLI2909.1.

Vicente-Serrano, S. M., S. Beguería, J. I. López-Moreno, M. Angulo, and A. El Kenawy. 2010b. A New Global $0.5^{\circ}$ Gridded Dataset (1901-2006) of a Multiscalar Drought Index: Comparison with Current Drought Index Datasets Based on the Palmer Drought 
Severity Index. J. Hydrometeor. 11:1033-1043, doi:http://dx.doi.org/10.1175/2010JHM1224.1.

Wang, C., and S. K. Lee. 2007. Atlantic warm pool, Caribbean low-level jet, and their potential impact on Atlantic hurricanes. Geophys. Res. Lett. 34:L02703, doi:10.1029/2006GL028579.

Wang, C., S. K. Lee, and D. B. Enfield. 2008. Atlantic Warm Pool acting as a link between Atlantic Multidecadal Oscillation and Atlantic tropical cyclone activity. Geochem. Geophys. Geosyst. 9:Q05V03, doi:10.1029/2007GC001809.
Whyte, F. S., M. A. Taylor, T.S. Stephenson and J.D. Campbell. 2008. Features of the Caribbean low level jet. Int. J. Climatol. 28:119-128, doi:10.1002/ joc. 1510 .

Zeng, N., et al. 2008. Causes and impacts of the 2005 Amazon drought. Envi. Res. Lett. 3(1):014002, doi:10.1088/1748-9326/3/1/014002.

Zhou, Jiansong, Ka-Kit Tung. 2013. Deducing Multidecadal Anthropogenic Global Warming Trends Using Multiple Regression Analysis. J. Atmos. Sci. 70:3-8. 